\title{
A Variant C178T in the Regulatory Region of the Serotonin Receptor Gene HTR3A Modulates Neural Activation in the Human Amygdala
}

\author{
Tetsuya Iidaka, ${ }^{1,5}$ Norio Ozaki, ${ }^{2}$ Atsushi Matsumoto, ${ }^{1}$ Junpei Nogawa, ${ }^{1}$ Yoko Kinoshita, ${ }^{3}$ Tatsuyo Suzuki, ${ }^{3}$ Nakao Iwata, ${ }^{3}$ \\ Yukiko Yamamoto, ${ }^{4}$ Tomohisa Okada, ${ }^{4}$ and Norihiro Sadato ${ }^{4,5}$ \\ ${ }^{1}$ Department of Psychology, Graduate School of Environmental Studies, and ${ }^{2}$ Department of Psychiatry, Graduate School of Medicine, Nagoya University, \\ Nagoya, Aichi 464-8601, Japan, ${ }^{3}$ Department of Psychiatry, School of Medicine, Fujita Health University, Toyoake 470-1192, Japan, ${ }^{4}$ Department of Cerebral \\ Research, National Institute for Physiological Sciences, Okazaki 444-8585, Japan, and 5Japan Science and Technology Corporation/Research Institute of \\ Science and Technology for Society, Kawaguchi 332-0012, Japan
}

Converging evidence in neurophysiological and neuroimaging studies has suggested that the limbic and prefrontal systems play important roles in emotion and cognition. These structures are activated when we see a human face, assuming that we automatically evaluate the biological significance of the stimuli. The serotonin (5-HT) system within the brain has been tied to various behaviors such as mood and anxiety and to the biology of neuropsychiatric disorders. To investigate the link between the 5-HT system and limbic/prefrontal activity, normal subjects $(n=26)$ who underwent functional magnetic resonance imaging and faced recognition tasks were genotyped for the single nucleotide polymorphism $\mathrm{C178T}$ in the regulatory region of the serotonin receptor type 3 gene (HTR3A). We found that the subjects with $\mathrm{C} / \mathrm{C}$ alleles had greater activity in the amygdala and dorsal and medial prefrontal cortices than those with $\mathrm{C} / \mathrm{T}$ alleles. The $\mathrm{C} / \mathrm{C}$ group also showed a faster reaction time during the task than the $\mathrm{C} / \mathrm{T}$ group. The temperamental predisposition of the subjects had a significant correlation with brain activity in the $\mathrm{C} / \mathrm{C}$ group. The genotype effect in the right amygdala and prefrontal cortex was largest during the first run of the experiment. These results indicate that the C178T variation in the HTR $3 A$ has a critical influence on the amygdaloid activity and on human face processing, probably through regulation of the receptor expression. The present study may contribute to elucidating a possible link among genes, the brain, and behavior in normal populations and may help reveal the biological basis of neuropsychiatric disorders.

Key words: fMRI; face; limbic system; reaction time; personality; habituation

\section{Introduction}

Serotonin (5-HT) plays a significant role in the biological basis of human behaviors, psychiatric diseases (Meltzer, 1990), and temperamental predisposition (Reif and Lesch, 2003). Among the several subtypes of 5 -HT receptors, the type 3 receptor $\left(5-\mathrm{HT}_{3}\right)$ uniquely belongs to the superfamily of ligand-gated ionotropic receptors (Turner et al., 2004) and relates with cognitive and emotive functions in humans (Olivier et al., 2000). This may be explained by the finding that the $5-\mathrm{HT}_{3}$ receptor is distributed in the amygdala, hippocampus, and cingulate cortex (Tecott et al., 1993; Bloom and Morales, 1998; Morales et al., 1998). Although the precise role of this receptor subtype is still elusive, several authors have suggested that the $5-\mathrm{HT}_{3}$ receptor inhibits memory and learning in the amygdala (Koyama et al., 2000) and hippocampus (Staubli and Xu, 1995; Bloom and Morales, 1998)

\footnotetext{
Received May 16, 2004; revised May 16, 2005; accepted May 31, 2005.

This work was supported in part by research grants from the Japanese Ministry of Education, Culture, Sports, Science, and Technology and the Japanese Ministry of Health, Labor, and Welfare.

Correspondence should be addressed to Dr. Tetsuya lidaka, Department of Psychology, Graduate School of Environmental Studies, Nagoya University, Chikusa, Nagoya, Aichi 464-8601, Japan. E-mail: iidaka@info.human.nagoya-u.ac.jp.

D0I:10.1523/JNEUROSCI.5261-04.2005

Copyright $\odot 2005$ Society for Neuroscience $\quad 0270-6474 / 05 / 256460-07 \$ 15.00 / 0$
}

through the GABAergic inhibitory mechanism (Turner et al., 2004).

The $5-\mathrm{HT}_{3}$ receptor gene $(H T R 3 A$ and $H T R 3 B)$ has been cloned for mice (Maricq et al., 1991) and humans (Miyake et al., 1995) and assigned to a single locus at human chromosome 11 (11q23.1-23.2) (Miyake et al., 1995; Weiss et al., 1995; Bruss et al., 2000). Several authors have indicated that major psychiatric disorders such as schizophrenia (Craddock and Lendon, 1999) and affective disorder (Detera-Wadleigh et al., 1998; Baysal et al., 2002) are associated with a chromosome abnormality involving distal 11q. In an in vitro study, a single nucleotide polymorphism (SNP), C178T, in the upstream regulatory region of the HTR3A gene has been found to regulate receptor expression by affecting the translation rate of HTR3A (Niesler et al., 2001). The authors suggested that the less common $\mathrm{T}$ allele was related to an increase of HTR3A expression compared with the more common C allele (Niesler et al., 2001). Recently, two studies demonstrated that the $\mathrm{C} 178 \mathrm{~T}$ polymorphism is relevant to the biological mechanisms of affective disorder (Nielser et al., 2001) and the personality trait of harm avoidance (HA) (Melke et al., 2003). Therefore, it is particularly important to investigate the functional relevance of this SNP and brain activity in normal human subjects.

For this purpose, 26 subjects who underwent functional mag- 
Table 1. Demographic characteristics, personality/depression score, and 5-HTTLPR genotype of the $\mathrm{C} / \mathrm{C}$ and $\mathrm{C} / \mathrm{T}$ groups

\begin{tabular}{lcc}
\hline C178T genotype & C/C & $C / T$ \\
\hline Number of subjects & 15 & 11 \\
Sex (male/female) & $6 / 9$ & $7 / 4$ \\
Mean age & $23.4(3.8)$ & $21.6(2.1)$ \\
Education (years) & $15.8(1.5)$ & $15.6(1.2)$ \\
TCI & & \\
$\quad$ HA & $12.0(4.8)$ & $11.1(4.3)$ \\
NS & $9.8(4.1)$ & $9.9(4.1)$ \\
RD & $9.5(1.9)$ & $9.9(2.8)$ \\
Persistence & $2.4(1.1)$ & $2.6(1.2)$ \\
BDI & $3.9(4.1)$ & $4.0(4.6)$ \\
5-HTTLPR & $\mathrm{s} / \mathrm{s}, 10 ; \mathrm{s} / \mathrm{l}, 5$ & $\mathrm{~s} / \mathrm{s}, 4 ; \mathrm{s} / \mathrm{l}, 5 ; \mathrm{l} / \mathrm{l}, 2$ \\
\hline
\end{tabular}

Values are the mean and SD of each group. The ethnicity of the subjects is Japanese. 5-HTTLPR, Number of subjects in each genotype.

netic resonance imaging ( $\mathrm{fMRI}$ ) and a face recognition task were genotyped, and the blood oxygen level-dependent (BOLD) signal changes were compared between groups with different genotypes. During the task, pictures of unfamiliar faces with neutral expressions or pictures of houses were presented. The subjects were instructed to determine whether the picture was of a face or house. Face recognition was used because this task has been shown to predominantly activate the amygdala in normal subjects (for review, see Zald, 2003). The subject's personality trait as measured by the Temperament and Character Inventory (TCI) scale (Cloninger, 1987) was examined in relation to the brain activity and genotype. We predicted that the signals in the amygdala would be reduced in subjects with a $\mathrm{T}$ allele, because this allele is associated with increased receptor expression (Nielser et al., 2001) and subsequently involves the GABAergic inhibitory mechanism (Turner et al., 2004). Furthermore, responses in the human amygdala have been shown to change across experimental runs (Breiter et al., 1996). In the present study, the experimental run was repeated three times to investigate the genetic modulation of habituation in amygdaloid activation.

\section{Materials and Methods}

Subjects. Twenty-six right-handed healthy subjects participated in the experiment after providing written informed consent. Demographic characteristics of the subjects are summarized in Table 1 . The study was approved by the ethics committee at the National Institute for Physiological Sciences and Fujita Health University and by the Institutional Review Board at the Nagoya University Graduate School of Environmental Studies. The subjects completed the Japanese versions of the Beck Depression Inventory (BDI) (Beck and Steer, 1993) and the TCI (125 items) (Cloninger, 1987)

Genotyping of C178T: PCR-restriction fragment length polymorphism. A blood sample was collected from each subject, and genomic DNA was extracted using standard methods. The primer pairs were $5^{\prime}$ TTTCCTCCCGCCTGAAAC-3' and 5'-AAGTCCTGCTGCTTCCCG$3^{\prime}$. DNA amplification was performed using an iCycler (Bio-Rad Laboratories Japan, Tokyo, Japan). The reaction mixture was in a $6 \mu$ l volume containing $10 \mathrm{ng}$ of sample DNA, a $0.25 \mathrm{~mm}$ concentration of each primer, and $200 \mathrm{~mm}$ each of deoxy NTP, $1 \times$ PCR Gold buffer, $2 \mathrm{~mm}$ $\mathrm{MgCl}_{2}, 5 \% \mathrm{DMSO}$, and $0.15 \mathrm{U}$ of AmpliTaq Gold (Applied Biosystems Japan, Tokyo, Japan). Initial denaturation at $95^{\circ} \mathrm{C}$ for 9 min was followed by 45 cycles of denaturation at $95^{\circ} \mathrm{C}$ for $15 \mathrm{~s}$, primer annealing at $57^{\circ} \mathrm{C}$ for $20 \mathrm{~s}$, and primer extension at $72^{\circ} \mathrm{C}$ for $30 \mathrm{~s}$, with a final extension reaction at $72^{\circ} \mathrm{C}$ for $7 \mathrm{~min}$. Then, $6 \mu \mathrm{l}$ of the PCR product was digested with $1 \mathrm{U}$ of restriction enzyme, Hpy188III, according to the manufacturer's recommendations. DNA fragments were resolved by electrophoresis in a $6 \%$ acrylamide gel stained with ethidium bromide. In addition to the $\mathrm{C} 178 \mathrm{~T}$ polymorphism of HTR3A, the subjects were genotyped for the
5-HTTLPR polymorphism according to the method described by Lesch et al. (1996).

Experimental procedure. Digitized grayscale pictures of 48 faces with neutral expressions taken from posers (24 males and 24 females) and pictures of 20 houses created using computer graphics software (AskaPro; Logic, Kanazawa, Japan) served as the stimuli (Iidaka et al., 2001). These pictures were divided into two sets of stimuli, which were assigned randomly to each subject. For each face picture, an inverted version and inverted-blurred version were created with equal luminance using commercial photographic software. In each run, 24 upright faces, 24 inverted faces, 24 inverted-blurred faces, 10 houses, and 24 null events with fixation were presented randomly. Each run was repeated three times with the same set of stimuli intermixed randomly. Although in the original experiment the inverted and inverted-blurred face conditions were included, the results for these conditions are not reported here. Hereafter, we will refer to the "upright face" condition as the "face" condition. Each subject saw these stimuli successively, one at a time, for $500 \mathrm{~ms}$ with an interstimulus interval of $4500 \mathrm{~ms}$. During the interval, a fixation point was shown. In the fMRI experiment, the stimuli were projected onto a transparent screen hanging on the bore of a magnet $75 \mathrm{~cm}$ from the subject's eyes. The subjects viewed the stimuli through a tilted mirror attached to the head coil of the scanner. All of the stimuli subtended a visual angle of $\sim 5.5 \times 7^{\circ}$. The subject was asked to judge whether the presented stimulus was a face or a house and press a corresponding button with his or her right hand. The reaction time (RT) for the task during the fMRI experiment was compared between genotypes using one-way ANOVA and is plotted in Figure 1.

fMRI data acquisition and analysis. Functional images of the entire brain were acquired in an axial orientation using a 3 tesla Siemens (Erlangen, Germany) Allegra MRI scanner equipped with single-shot echo planar image [EPI; repetition time (TR), $2.3 \mathrm{~s}$; echo time (TE), $30 \mathrm{~ms}$; flip angle, $80^{\circ}$; $64 \times 64$ matrix; 36 slices; voxel size, $3 \times 3 \times 3 \mathrm{~mm}$ ] sensitive to BOLD contrast (Ogawa et al., 1992). After discarding the first 6 images, the remaining 234 successive images in each run were subjected to analysis. A high-resolution anatomical T1-weighted image was also acquired (MPRAGE; TR, $2.5 \mathrm{~s}$; TE, $4.38 \mathrm{~ms}$; flip angle, $8^{\circ}$; $256 \times 256$ matrix; 192 slices; voxel size, $0.75 \times 0.75 \times 1 \mathrm{~mm}$ ) for each subject. The fMRI experiment was controlled using Presentation software (Neurobehavioral Systems, Albany, CA).

Data were analyzed by SPM99 (Wellcome Department of Imaging Neuroscience, London, UK). First, all volumes were realigned spatially to the final volume, and the signal in each slice was realigned temporally to that obtained in the middle slice using a sinc interpolation. The resliced volumes were normalized to the MNI (Montreal Neurological Institute) space (Evans et al., 1993) using a transformation matrix obtained from the normalization process of the mean EPI of each individual subject to the EPI template. The normalized images were spatially smoothed with an $8 \mathrm{~mm}$ Gaussian kernel.

After preprocessing, statistical analysis of each individual subject was conducted using the general linear model (Friston et al., 1995). At the first level, each single event was modeled as a hemodynamic response function and its temporal derivative. Low-pass and high-pass frequency filters were applied to the time-series data. For each subject, motion parameters were included as regressors of no interest to take into account the effects of head motion not removed at the realignment stage. The images were scaled to a grand mean of 100 over all voxels and scans within each session. In the subtraction analysis, five conditions (correct responses for the four experimental conditions and incorrect responses) were modeled separately. Parameter estimates for each condition and for the difference between the conditions were calculated from the leastmean-square fit of the model to the time-series data. Our particular interest was in the images of parameter estimates representing the difference in event-related activity between the face condition and house condition.

At the second-level (random-effects) analysis, we compared the brain activity between genotypes by entering contrast images of each individual subject containing parameter estimates representing activation for the face minus house condition into a two-sample $t$ test. The statistical threshold of the analysis was set at $p=0.001$, uncorrected for multiple 
comparisons for height; clusters were $>5$ voxels. This height threshold was chosen because the difference in amygdaloid activity between the genotypes was predicted as noted in the Introduction. Region names, coordinates, and $Z$ values for the difference between the genotypes are tabulated in Table 2. Amygdaloid and prefrontal regions with a significant group difference are shown in Figures 2 and 3, respectively. Signals extracted from the four regions with a significant group difference are plotted in Figure 4 . These signals were extracted from the spherical regions of interest that were drawn on each region with a radius of $8 \mathrm{~mm}$ using MarsBaR software (Brett et al., 2002). As supplementary analyses, the subject's age or sex (male or female as a categorical variable) was included in the analysis of covariance to exclude the effect of these factors from the results for group differences.

To examine the relationship between the temperamental predisposition, genotype, and brain responses, multiple regression analyses were conducted using the score of the TCI subscale, the signal change in the amygdala and prefrontal areas, and the genotype as variables (Hariri et al., 2005). Significance of the interaction effect of genotype and BOLD signal on the TCI subscale was tested at the $p=0.05$ level. The correlations between the right amygdala activity and HA score, between the right superior frontal gyrus activity and novelty-seeking (NS) score, and between the medial prefrontal activity and reward dependence (RD) score are plotted in Figure 6.

To test whether the temporal pattern of activation differs between the genotypes, the contrast image of the face minus house condition was created separately for each run. Separate ANOVAs with the RT as a covariate were conducted for the first, second, and third runs at the threshold of $p=0.001$, uncorrected, and $\mathrm{k}=10$ voxels. The analysis was restricted to the right amygdala and prefrontal cortices where significant group difference was observed. Signal changes during each run were extracted from the right amygdala and superior frontal gyrus and are shown in Figure 7. The results shown in Tables 1 and 2 and in Figures 1-6 are from the analyses collapsing the three experimental runs.

\section{Results}

\section{Genomic data}

For the C178T polymorphism, 15 subjects had C/C alleles and 11 subjects had $\mathrm{C} / \mathrm{T}$ alleles (Table 1 ). The genotypes were distributed according to the Hardy-Weinberg equilibrium. These two groups did not differ significantly in terms of mean age (Kruskal-Wallis test; $p=0.24)$, sex $\left(\chi^{2}=1.41 ; p=0.23\right)$, or years of education $(F=0.02 ; p=0.88)$. The proportion of each of the 5 -HTTLPR variants did not differ significantly between the $\mathrm{C} / \mathrm{C}$ and $\mathrm{C} / \mathrm{T}$ groups $\left(\chi^{2}=4.05 ; p=0.13\right)$.

\section{Behavioral data}

The mean RT and accuracy for the face recognition task during the fMRI experiment were $413 \pm 46 \mathrm{~ms}$ and $97 \pm 5 \%$, respectively. One-way ANOVA showed that the main effect of the genotype on the mean RT was significant $(F=5.26 ; p=0.03)$. The subjects with $\mathrm{C} / \mathrm{C}$ alleles had faster RTs than those with $\mathrm{C} / \mathrm{T}$ alleles ( $398 \pm 48$ vs $437 \pm 31 \mathrm{~ms}$ ), as plotted in Figure 1 . There was no significant group difference in accuracy during the fMRI experiment $(F=1.83 ; p=0.18)$. Neither the mean of the BDI score nor that of the four TCI subscales differed significantly between the genotypes (Table 1).

\section{Neuroimaging data}

There were several brain regions where the signal change in response to face stimuli compared with house stimuli was significantly greater for the subjects with $\mathrm{C} / \mathrm{C}$ alleles than for those with

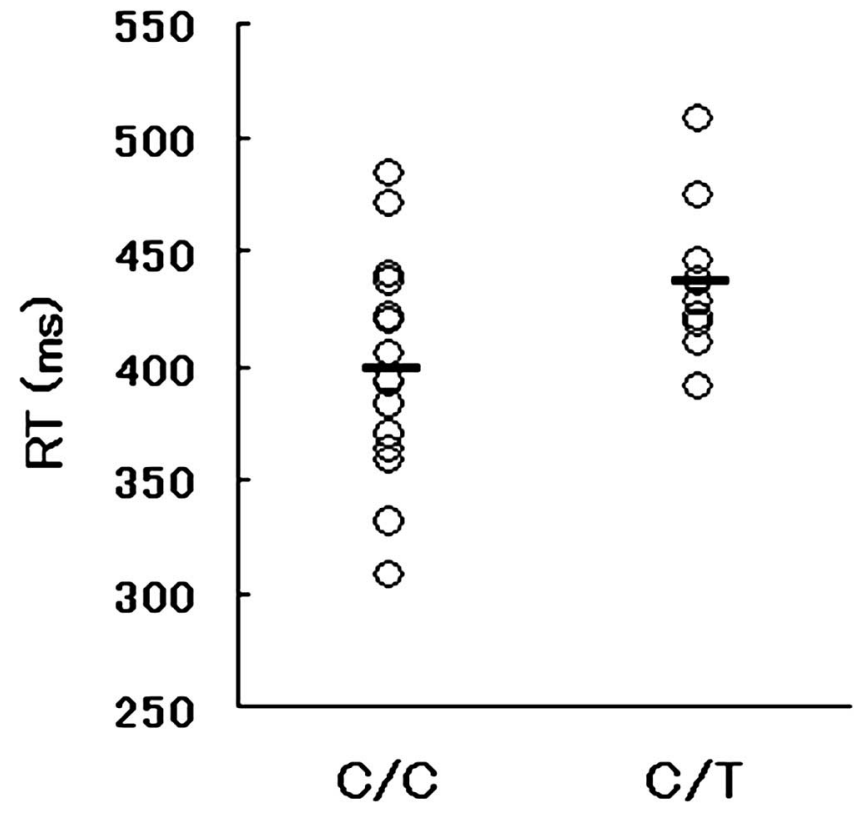

Figure 1. Reaction time (RT) during the fMRI experiment in each individual subject and group; the mean value (horizontal bar) is shown. The C/C group had a significantly faster mean RT than the C/T group.

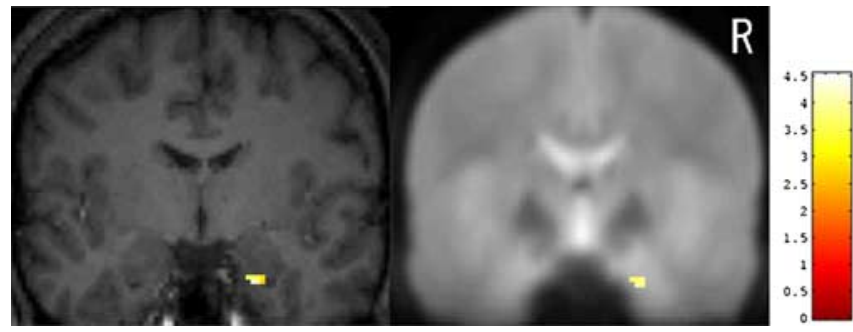

Figure 2. The right amygdala with significant group differences in activation measured by fMRI is superimposed on a high-resolution T1-weighted image of a single subject (left) and on a mean EPI of 26 subjects (right). Coronal images are shown at $y=-4 \mathrm{~mm}$. In this region, the signal was greater for the $\mathrm{C} / \mathrm{C}$ group than for the $\mathrm{C} / \mathrm{T}$ group. For coordinates, voxel size, and $Z$ values, see Table 2. R, Right.

$\mathrm{C} / \mathrm{T}$ alleles. These regions were located in the right amygdala (Fig. 2), right prefrontal cortex (Fig. 3), supplementary motor area, and left intraparietal sulcus (Table 2). A cluster in the right fusiform gyrus showed greater activation in the $\mathrm{C} / \mathrm{T}$ group than in the $\mathrm{C} / \mathrm{C}$ group. These six regions survived small volume correction for height within an $8 \mathrm{~mm}$ sphere at the $p=0.05$ level. The regions also remained significant ( $p=0.001$, uncorrected) when the subject's age or sex was included in the analysis as a nuisance covariate. The degree of activation in the peak voxel listed in 


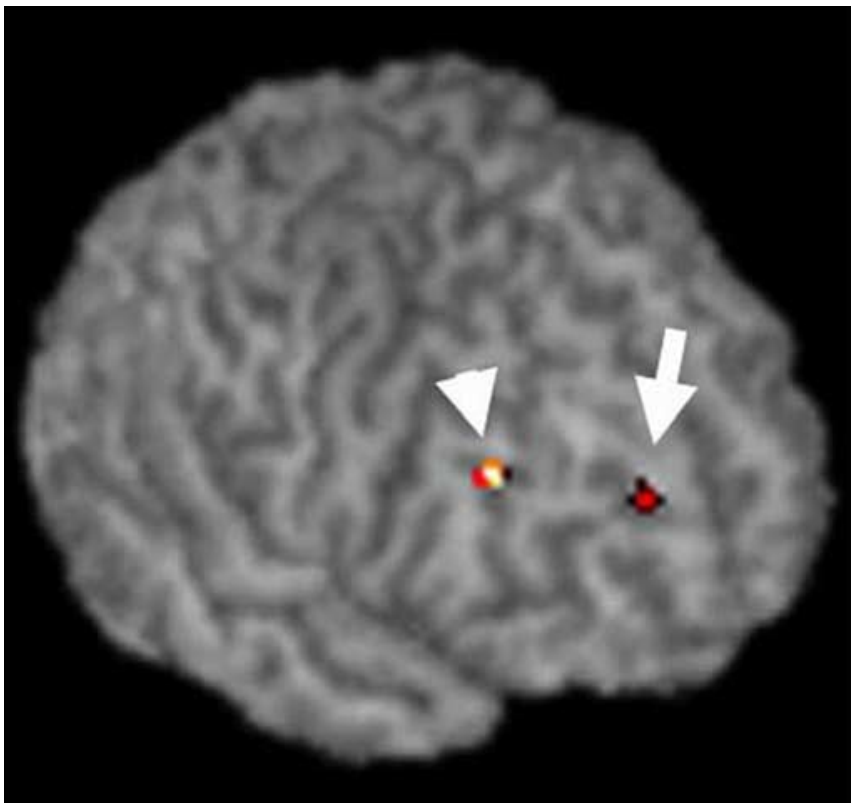

Figure 3. The areas on the right superior frontal gyrus (BA10; arrow) and middle frontal gyrus (BA9; arrowhead) where the signal was greater for the $\mathrm{C} / \mathrm{C}$ group than for the $\mathrm{C} / \mathrm{T}$ group are rendered on the surface of a single subject's brain. For coordinates, voxel size, and $Z$ values, see Table 2.

Table 2 did not differ between male and female subjects in either the $\mathrm{C} / \mathrm{C}$ or $\mathrm{C} / \mathrm{T}$ group at a lenient threshold ( $p=0.05$, uncorrected). The signals extracted from four regions in each individual subject are plotted in Figure 4. When two subjects with the 1/1 genotype of the 5-HTTLPR variant were excluded from the analysis, the six regions listed in Table 2 showed significant difference in activation between the C178T genotypes ( $p=0.001$, uncorrected). Therefore, the effects of $\mathrm{C} 178 \mathrm{~T}$ variants on activity in the amygdala and other regions do not simply reflect the influence of the 5-HTTLPR genotype.

In addition to these regions, we were particularly interested in the medial prefrontal cortex [mPFC; Brodmann's area 9 (BA9)] (Fig. 5, $x, y, z=-10,52,32$ ), which survived the height threshold ( $z=3.14 ; p=0.001$, uncorrected) but not the extent threshold ( $k=3$ voxels), because this region has reciprocal connection with the amygdala (Ongur and Price, 2000). As shown in the right side of Figure 5, the mPFC activity positively correlated with the amygdaloid activity across all 26 subjects, suggesting that these two regions may have a functional relationship during the face recognition task. To examine whether the functional coupling of the amygdala and mPFC would be modulated by genotype or experimental run, the correlation coefficient was computed separately for each run and genotype. A positive correlation was significant only during the first $(r=0.58 ; p<0.05)$ and second $(r=0.58 ; p<0.05)$ runs in the $\mathrm{C} / \mathrm{C}$ group.

The functional relationship between the temperamental predisposition as measured by the TCI subscale and BOLD signal is modulated by the C178T genotype as shown in Figure 6. The right amygdala activity is significantly and negatively correlated with the HA score in the $\mathrm{C} / \mathrm{C}$ group $(r=-0.69 ; p=0.004)$ but not in the $\mathrm{C} / \mathrm{T}$ group $(r=0.21 ; p=0.52)$. Activity in the right superior frontal gyrus (BA10) had a significant positive correlation with the NS score in the C/C group $(r=0.51 ; p=0.03)$ but not in the $\mathrm{C} / \mathrm{T}$ group $(r=-0.41 ; p=0.19)$. Finally, the RD score significantly and negatively correlated with $\mathrm{mPFC}$ (BA9) activity in the $\mathrm{C} / \mathrm{C}$ group $(r=-0.57 ; p=0.02)$ but not in the $\mathrm{C} / \mathrm{T}$ group
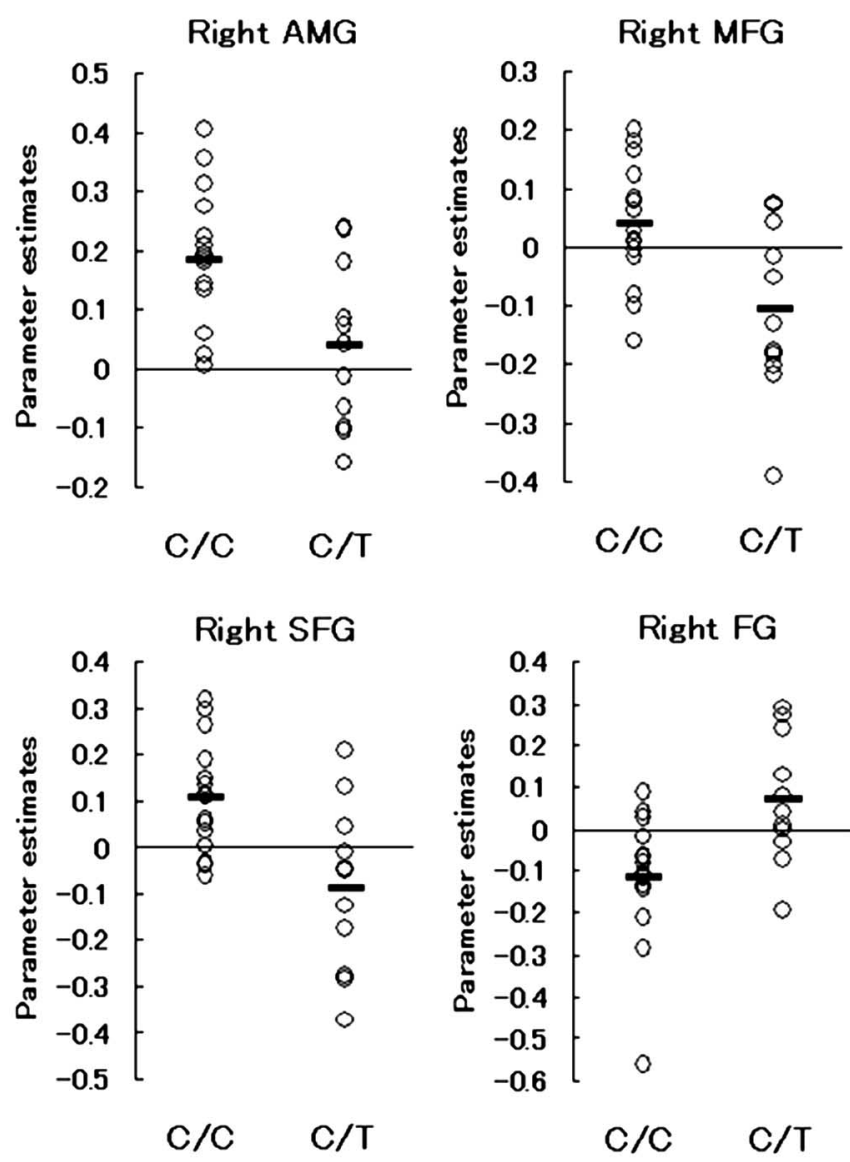

Figure 4. Signal changes in response to face stimuli compared with house stimuli in each subject extracted from spherical ROIs $(r=8 \mathrm{~mm})$ at the right amygdala (AMG), middle frontal gyrus (MFG; BA9), superior frontal gyrus (SFG; BA10), and fusiform gyrus (FG; BA37) are shown. The horizontal bar indicates the group mean.

$(r=0.51 ; p=0.37)$. In these cases, multiple regression analyses showed a significant genotype-by-BOLD interaction effect on the $\mathrm{HA}(p<0.05)$, NS $(p<0.05)$, and RD $(p<0.01)$ scores.

\section{Temporal pattern of activation}

The right amygdala $(x, y, z=26,-4,-28)$ and superior frontal gyrus (BA10; $x, y, z=18,50,24)$ showed a significant difference in activation between the genotypes only during the first run when the difference in the RT was taken into account. As shown in Figure 7, the subjects with $\mathrm{C} / \mathrm{C}$ alleles had higher signals in these regions than those with $\mathrm{C} / \mathrm{T}$ alleles, particularly during the first run. We conducted two-way ANOVA with a GreenhouseGeisser correction for the run (within subjects) and genotype (between subjects) as factors on signal and RT data. There was a significant interaction effect of the run and genotype on the BOLD signal (amygdala: $F=3.85, p<0.05$; superior frontal gyrus: $F=4.39, p<0.05)$. A post hoc $t$ test showed that the genotype effect was significant during the first $(p<0.01)$ and third $(p<0.05)$ runs for the amygdala and during the first run $(p<0.01)$ for the prefrontal cortex. The interaction effect of the run and genotype on the RT was not significant.

\section{Discussion}

Combined neurophysiological and genetic studies have been suggested as an important research strategy in the field of neuroscience (Begleiter et al., 1984; Porjesz et al., 2002; Hariri and Weinberger, 2003). The study by Hariri et al. (2002) showed an 
association between amygdaloid activity and the 5-HT transporter gene had an impact on research into mood disorders, because 5-HT is known to be related to depression and stressful life events (Caspi et al., 2003). The present study, in a similar vein as their report, investigated whether the $\mathrm{SNP}, \mathrm{C} 178 \mathrm{~T}$, in the upstream regulatory region of the HTR $3 A$ gene would modulate brain activity in the limbic areas during a face recognition task. There were significant differences in the BOLD signals measured in the right amygdala and prefrontal cortices between the subjects with $\mathrm{C} / \mathrm{C}$ alleles and those with $\mathrm{C} / \mathrm{T}$ alleles. These effects were not simply a reflection of the 5-HTTLPR variants of the subjects. The two groups of subjects also differed in the RT obtained during the fMRI experiment. In addition, the genetic effect on the relationship between the temperament and BOLD signal was significant. In the right amygdala and prefrontal regions, the temporal pattern of activation across runs was modulated by genotype. The present findings indicate a possible role of this genetic polymorphism in face processing through neural responses in the amygdala and prefrontal system, which underlie complex human behaviors.

The group fMRI analysis clearly showed that the degree of activation in the right amygdala differed between the subjects with $\mathrm{C} / \mathrm{C}$ alleles and those with $\mathrm{C} / \mathrm{T}$ alleles. Changes in the BOLD signal imply changes in the local concentration of oxy-/deoxyhemoglobin (Ogawa et al., 1992), but not the direct synaptic activity associated with the release and the receptor binding of particular neurotransmitters. However, several findings indicate that the genetic polymorphism of the $5-\mathrm{HT}_{3}$ system may alter hemodynamic responses in specific regions of the human brain during cognitive tasks. First, the $5-\mathrm{HT}_{3}$ receptor is preferentially expressed in the amygdala and the cingulate gyrus in animals and humans (Tecott et al., 1993; Bloom and Morales, 1998; Morales et al., 1998). Second, in an in vitro study, the T allele of the C178T polymorphism has been suggested to regulate receptor expression by enhancing the translation rate of the downstream HTR3A (Niesler et al., 2001). Third, a positron emission tomographic study showed that administration of the $5-\mathrm{HT}_{3}$ receptor antagonist altered the amygdaloid blood flow in human subjects (Berman et al., 2002). Finally, in vitro studies found that the specific $5-\mathrm{HT}_{3}$ receptor agonist facilitates inhibitory GABA release in the amygdala (Koyama et al., 2000), hippocampus (Turner et al., 2004), and other areas (Bloom and Morales, 1998). These results may suggest that the right amygdaloid function in the subjects with a $\mathrm{T}$ allele is inhibited by enhanced receptor expression and GABAergic neurotransmission.

In addition to the limbic regions, two dorsolateral prefrontal cortices had greater activation in the $\mathrm{C} / \mathrm{C}$ group than in the $\mathrm{C} / \mathrm{T}$ group. These areas are particularly involved in the processes of working memory and episodic encoding of nonverbal materials such as human faces (Kelley et al., 1998). Higher-order operations on facial information in the prefrontal cortex may be conducted extensively in the subjects with $\mathrm{C} / \mathrm{C}$ alleles. In contrast, activity in the right fusiform gyrus, a region that is sensitive to the human face (Allison et al., 1994), was greater in the C/T group than in the $\mathrm{C} / \mathrm{C}$ group. This may be as a result of the subjects with the $\mathrm{T}$ allele relying more heavily on the visual cortical pathway to process the stimuli than the other subjects, who used the amygdala-mediated subcortical route. Strong right-lateralization of activation would be attributable to that the right hemisphere is more specialized for face processing in human subjects than the left hemisphere (Sergent and Bindra, 1981).

A novel finding of the present study is that the relationship between the TCI score and brain response was modulated by genotype, although the mean TCI score did not differ between the two groups. A significant negative correlation between HA and amygdaloid activity may imply that enhanced 5-HT function in those with a high HA score reduced neural response in the limbic region in the C/C group (Del-Ben et al., 2005). A positive correlation between activity in the superior frontal gyrus and the NS in the $\mathrm{C} / \mathrm{C}$ group may relate to that the subjects with high extraversion scores having greater prefrontal activation during working memory tasks than those with low extraversion scores (Kumari et al., 2004). Finally, the correlation between the medial prefrontal activity and $\mathrm{RD}$ may be underpinned by the evidence that the medial prefrontal-limbic circuit subserves reward processing in experimental animals (Wise, 2000).

The RT during the fMRI experiment differed between the genotypes, indicating that the subjects with the $\mathrm{T}$ allele do not process face stimuli as fast as those who are homozygous for the $\mathrm{C}$ allele. Amygdaloid function has been implicated in conditioned associative learning (Ono et al., 1995) and in the processing of stimuli with biological significance in multiple sensory domains (Zald, 2003). The amygdala is a part of the subcortical information pathway that bypasses the primary visual cortex to respond rapidly to salient stimuli (Morris et al., 1999; Adolphs, 2002). The present results may suggest, in accordance with this model, that a shorter mean $\mathrm{RT}$ in the $\mathrm{C} / \mathrm{C}$ group is a reflection of activation in the amygdala-mediated subcortical pathway. The result that the $\mathrm{C} / \mathrm{T}$ group, which used the right fusiform gyrus during the task, responded more slowly than the $\mathrm{C} / \mathrm{C}$ group fits with this hypothesis.

Neuroimaging studies in normal subjects have shown that the amygdaloid and prefrontal responses to face stimuli are largest during the initial phase of the experiment (Breiter et al., 1996; Wright et al., 2001). In contrast, an fMRI study showed that the peak of the amygdaloid response in depressed subjects occurred later in the time course than that in control subjects (Siegle et al., 2002). Therefore, we hypothesized that the genotype effect in the amygdala would be found predominantly during the first run of the experiment. As shown in Figure 7, the difference in activation between the groups was largest during the first run in the right amygdala and superior frontal gyrus. The $\mathrm{C} / \mathrm{C}$ group showed a 

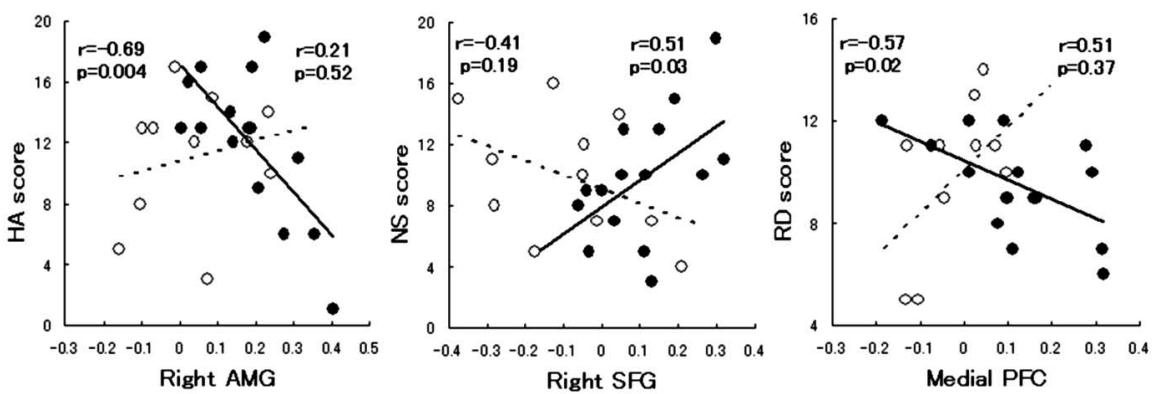

Figure 6. Correlations between the $\mathrm{TCl}$ subscale score and the brain activity are plotted separately for each genotype group. Left, Harm avoidance (HA) score and right amygdaloid activity. AMG, Amygdala. Middle, Novelty-seeking (NS) score and activity in the right superior frontal gyrus (SFG; BA10). Right, Reward dependence (RD) score and medial prefrontal cortex (PFC; BA9) activity. Filled circles indicate subjects with C/C alleles, and open circles indicate subjects with $C / T$ alleles. The regression lines $(C / C$ group, solid line; (/T group, dotted line), correlation coefficients, and $p$ values are also shown.

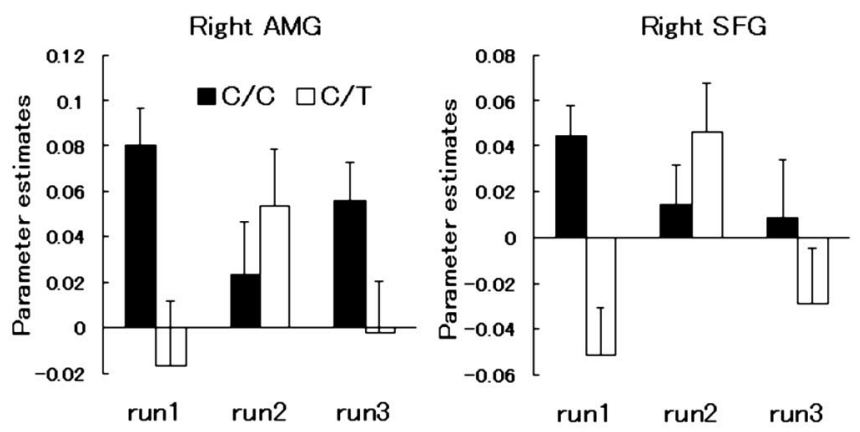

Figure 7. The mean and SE of the right amygdala (AMG; $x, y, z=24,-4,-30$ ) and prefrontal [superior frontal gyrus (SFG); BA10; $x, y, z=18,52,24$ ] responses to face stimuli in each group of subjects during the first (run1), second (run2), and third (run3) runs of the fMRI experiment are shown. $\square$, C/C group; $\square$, C/T group.

typical temporal pattern of activation, whereas in the $\mathrm{C} / \mathrm{T}$ group, the peak was observed in the second run. Reduced activation and the differential habituation pattern would be related to disturbance in stress hormone response through the 5-HT system (Van Praag, 2004).

Another significant finding was that the $\mathrm{MPFC}$ activation was greater in the $\mathrm{C} / \mathrm{C}$ group than in the $\mathrm{C} / \mathrm{T}$ group and positively correlated with the amygdaloid activation. Functional coupling of $\mathrm{mPFC}$ and the amygdala was significant during the first and the second runs in the subjects with $\mathrm{C} / \mathrm{C}$ alleles. The mPFC plays a role in reward processing and goal-directed behavior in animals (Wise, 2000) and in humans (Rogers et al., 2004) and exerts significant control over the emotional-cognitive aspect of behavior (Vertes, 2004). Neuroanatomical studies in animals have shown that the mPFC has reciprocal connections with several nuclei of the amygdala (Ongur and Price, 2000), thalamus, and brainstem (Vertes, 2004) and relates with hormonal response to stress through the hypothalamic-pituitary-adrenal axis (Crane et al., 2003).

The present results have clinical implications in neuropsychiatry, because the C178T variant was more frequently found in bipolar affective patients than in a control group (Nielser et al., 2001). Differential BOLD signals and blood flow activation in the region of the amygdala, compared with normal subjects, have been observed in patients with mood disorders (Drevets, 2003) and anxiety disorders (Anand and Shekhar, 2003). An increased stress hormone level found in patients with depression and an anxiety disorder (Van Praag, 2004) is a biological marker of susceptibility to socio-psychological stress. Therefore, it is suggested that the subjects with the $\mathrm{T}$ allele and an increased 5- $\mathrm{HT}_{3}$ receptor expression (Nielser et al., 2001) may have an elevated hormonal level because the $5-\mathrm{HT}_{3}$ receptor is related to ACTH secretion in response to acute stress (Bhatnagar et al., 2004).

There are several caveats in the present study. First, the number of subjects is small and differed between the groups. In the future, a study with a larger number of subjects should be conducted. Second, the amygdala activity might have been limited because we used neutral faces, which elicit less activation in this region than faces expressing emotion, as stimuli. Third, the fact that there were no significant differences in the mean TCI subscale scores or BDI score between the genotypes may have obscured the functional relevance of the amygdala to personality and emotion. However, a recent study of HTR3A polymorphism and personality traits also showed no differences in the HA scores between the $\mathrm{C} / \mathrm{C}$ and $\mathrm{C} / \mathrm{T}$ groups (Melke et al., 2003). Neurophysiological responses as measured by fMRI would be more sensitive than questionnaires such as the BDI and TCI for detecting group differences. Neural activation in the amygdala should be treated as an endophenotype underlying both normal and pathological brain functions (Almasy and Blangero, 2001).

In conclusion, the present study, to the best of our knowledge, revealed for the first time the significant effect of HTR3A polymorphism on the amygdala and prefrontal activity as measured by fMRI. In addition, it showed that the difference in behavioral performance during a face recognition task was related to the genetic variation, indicating a close coupling of genes, behavior, and neurophysiological responses. The present findings may have clinical implications in predicting an individual's vulnerability to socio-psychological stressors before the onset of neuropsychiatric disorders. However, the causal relationship between genotype and brain activation is not fully elucidated in the present study. Therefore, additional investigation involving in vitro as well as in vivo experiments using animals, normal volunteers, and clinical populations are needed in the future.

\section{References}

Adolphs R (2002) Neural systems for recognizing emotion. Curr Opin Neurobiol 12:169-177.

Allison T, Ginter H, McCarthy G, Nobre AC, Puce A, Luby M, Spencer DD (1994) Face recognition in human extrastriate cortex. J Neurophysiol 71:821-825.

Almasy L, Blangero J (2001) Endophenotypes as quantitative risk factors for psychiatric disease: rationale and study design. Am J Med Genet 105:42-44.

Anand A, Shekhar A (2003) Brain imaging studies in mood and anxiety disorders: special emphasis on the amygdala. Ann NY Acad Sci 985:370-388

Baysal BE, Willett-Brozick JE, Badner JA, Corona W, Ferrell RE, Nimgaonkar VL, Detera-Wadleigh SD (2002) A mannosyltransferase gene at 11q23 is disrupted by a translocation breakpoint that co-segregates with bipolar affective disorder in a small family. Neurogenetics 4:43-53.

Beck AT, Steer RA (1993) Manual for the Beck Depression Inventory. San Antonio, TX: Psychological Corporation.

Begleiter H, Porjesz B, Bihari B, Kissin B (1984) Event-related brain potentials in boys at risk for alcoholism. Science 225:1493-1496.

Berman SM, Chang L, Suyenobu B, Derbyshire SW, Stains J, Fitzgerald L, Mandelkern M, Hamm L, Vogt B, Naliboff BD, Mayer EA (2002) 
Condition-specific deactivation of brain regions by $5-\mathrm{HT}_{3}$ receptor antagonist Alosetron. Gastroenterology 123:969-977.

Bhatnagar S, Sun LM, Raber J, Maren S, Julius D, Dallman MF (2004) Changes in anxiety-related behaviors and hypothalamic-pituitary-adrenal activity in mice lacking the 5-HT-3A receptor. Physiol Behav 81:545-555.

Bloom FE, Morales M (1998) The central 5- $\mathrm{HT}_{3}$ receptor in CNS disorders. Neurochem Res 23:653-659.

Breiter HC, Etcoff NL, Whalen PJ, Kennedy WA, Rauch SL, Buckner RL, Strauss MM, Hyman SE, Rosen BR (1996) Response and habituation of the human amygdala during visual processing of facial expression. Neuron 17:875-887.

Brett M, Anton J, Valabregue R, Poline JP (2002) Region of interest analysis using an SPM toolbox. Paper presented at Eighth International Conference on Functional Mapping of the Human Brain, Sendai, Japan, June.

Bruss M, Eucker T, Gothert M, Bonisch H (2000) Exon-intron organization of the human 5- $\mathrm{HT}_{3 \mathrm{~A}}$ receptor gene. Neuropharmacology 39:308-315.

Caspi A, Sugden K, Moffitt TE, Taylor A, Craig IW, Harrington H, McClay J, Mill J, Martin J, Braithwaite A, Poulton R (2003) Influence of life stress on depression: moderation by a polymorphism in the 5-HTT gene. Science 301:386-389.

Cloninger CR (1987) A systematic method for clinical description and classification of personality variants. A proposal. Arch Gen Psychiatry 44:573-588.

Craddock N, Lendon C (1999) Chromosome Workshop: chromosomes 11, 14, and 15. Am J Med Genet 88:244-254.

Crane JW, Ebner K, Day TA (2003) Medial prefrontal cortex suppression of the hypothalamic-pituitary-adrenal axis response to a physical stressor, systemic delivery of interleukin-1beta. Eur J Neurosci 17:1473-1481.

Del-Ben CM, Deakin JF, McKie S, Delvai NA, Williams SR, Elliott R, Dolan M, Anderson IM (2005) The effect of citalopram pretreatment on neuronal responses to neuropsychological tasks in normal volunteers: an fMRI study. Neuropsychopharmacology, in press.

Detera-Wadleigh SD, Yoshikawa T, Padigaru M, Berrettini WH, Badner JA, Sanders A, Goldin LR, Turner G, Rollins DY, Moses T, Esterling L, Gershon ES (1998) Genome screen and candidate gene analysis in bipolar disorder. Am J Med Genet 81:463.

Drevets WC (2003) Neuroimaging abnormalities in the amygdala in mood disorders. Ann NY Acad Sci 985:420-444.

Evans AC, Collins DL, Mills DR, Brown ED, Kelly RL, Peters TM (1993) 3D statistical neuroanatomical models from 305 MRI volumes. Proc IEEE Nucl Sci Symp Med Imaging 1-3:1813-1817.

Friston KJ, Holmes AP, Worsely KJ, Poline JP, Frith CD, Frackwiak RSJ (1995) Statistical parametric maps in functional imaging: a general linear approach. Hum Brain Mapp 2:189-210.

Hariri AR, Weinberger DR (2003) Imaging genomics. Br Med Bull 65:259-270.

Hariri AR, Mattay VS, Tessitore A, Kolachana B, Fera F, Goldman D, Egan MF, Weinberger DR (2002) Serotonin transporter genetic variation and the response of the human amygdala. Science 297:400-403.

Hariri AR, Drabant EM, Munoz KE, Kolachana BS, Mattay VS, Egan MF, Weinberger DR (2005) A susceptibility gene for affective disorders and the response of the human amygdala. Arch Gen Psychiatry 62:146-152.

Iidaka T, Omori M, Murata T, Kosaka H, Yonekura Y, Okada T, Sadato N (2001) Neural interaction of the amygdala with the prefrontal and temporal cortices in the processing of facial expressions as revealed by fMRI. J Cogn Neurosci 13:1035-1047.

Kelley WM, Miezin FM, McDermott KB, Buckner RL, Raichle ME, Cohen NJ, Ollinger JM, Akbudak E, Conturo TE, Snyder AZ, Petersen SE (1998) Hemispheric specialization in human dorsal frontal cortex and medial temporal lobe for verbal and nonverbal memory encoding. Neuron 20:927-936.

Koyama S, Matsumoto N, Kubo C, Akaike N (2000) Presynaptic 5- $\mathrm{HT}_{3}$ receptor-mediated modulation of synaptic GABA release in the mechanically dissociated rat amygdala neurons. J Physiol (Lond) 529:373-383.

Kumari V, ffytche DH, Williams SC, Gray JA (2004) Personality predicts brain responses to cognitive demands. J Neurosci 24:10636-10641.

Lesch KP, Bengel D, Heils A, Sabol SZ, Greenberg BD, Petri S, Benjamin J, Muller CR, Hamer DH, Murphy DL (1996) Association of anxietyrelated traits with a polymorphism in the serotonin transporter gene regulatory region. Science 274:1527-1531.

Maricq AV, Peterson AS, Brake AJ, Myers RM, Julius D (1991) Primary structure and functional expression of the $5 \mathrm{HT}_{3}$ receptor, a serotoningated ion channel. Science 254:432-437.
Melke J, Westberg L, Nilsson S, Landen M, Soderstrom H, Baghaei F, Rosmond R, Holm G, Bjorntorp P, Nilsson LG, Adolfsson R, Eriksson E (2003) A polymorphism in the serotonin receptor $3 \mathrm{~A}$ (HTR3A) gene and its association with harm avoidance in women. Arch Gen Psychiatry 60:1017-1023.

Meltzer HY (1990) Role of serotonin in depression. Ann NY Acad Sci 600:486-500

Miyake A, Mochizuki S, Takemoto Y, Akuzawa S (1995) Molecular cloning of human 5-hydroxytryptamine ${ }_{3}$ receptor: heterogeneity in distribution and function among species. Mol Pharmacol 48:407-416.

Morales M, Battenberg E, Bloom FE (1998) Distribution of neurons expressing immunoreactivity for the $5 \mathrm{HT}_{3}$ receptor subtype in the rat brain and spinal cord. J Comp Neurol 402:385-401.

Morris JS, Ohman A, Dolan RJ (1999) A subcortical pathway to the right amygdala mediating "unseen" fear. Proc Natl Acad Sci USA 96:1680-1685.

Niesler B, Flohr T, Nothen MM, Fischer C, Rietschel M, Franzek E, Albus M, Propping P, Rappold GA (2001) Association between the 5' UTR variant $\mathrm{C} 178 \mathrm{~T}$ of the serotonin receptor gene HTR3A and bipolar affective disorder. Pharmacogenetics 11:471-475.

Ogawa S, Tank DW, Menon R, Ellermann JM, Kim SG, Merkle H, Ugurbil K (1992) Intrinsic signal changes accompanying sensory stimulation: functional brain mapping with magnetic resonance imaging. Proc Natl Acad Sci USA 89:5951-5955.

Olivier B, van Wijngaarden I, Soudijn W (2000) 5- $\mathrm{HT}_{3}$ receptor antagonists and anxiety; a preclinical and clinical review. Eur J Neuropsychopharmacol 10:77-95.

Ongur D, Price JL (2000) The organization of networks within the orbital and medial prefrontal cortex of rats, monkeys and humans. Cereb Cortex 10:206-219.

Ono T, Nishijo H, Uwano T (1995) Amygdala role in conditioned associative learning. Prog Neurobiol 46:401-422.

Porjesz B, Almasy L, Edenberg HJ, Wang K, Chorlian DB, Foroud T, Goate A, Rice JP, O'Connor SJ, Rohrbaugh J, Kuperman S, Bauer LO, Crowe RR, Schuckit MA, Hesselbrock V, Conneally PM, Tischfield JA, Li TK, Reich T, Begleiter H (2002) Linkage disequilibrium between the beta frequency of the human EEG and a GABAA receptor gene locus. Proc Natl Acad Sci USA 99:3729-3733.

Reif A, Lesch KP (2003) Toward a molecular architecture of personality. Behav Brain Res 139:1-20.

Rogers RD, Ramnani N, Mackay C, Wilson JL, Jezzard P, Carter CS, Smith SM (2004) Distinct portions of anterior cingulate cortex and medial prefrontal cortex are activated by reward processing in separable phases of decision-making cognition. Biol Psychiatry 55:594-602.

Sergent J, Bindra D (1981) Differential hemispheric processing of faces: methodological considerations and reinterpretation. Psychol Bull 89:541-554.

Siegle GJ, Steinhauer SR, Thase ME, Stenger VA, Carter CS (2002) Can't shake that feeling: event-related fMRI assessment of sustained amygdala activity in response to emotional information in depressed individuals. Biol Psychiatry 51:693-707.

Staubli U, Xu FB (1995) Effects of 5- $\mathrm{HT}_{3}$ receptor antagonism on hippocampal theta rhythm, memory, and LTP induction in the freely moving rat. J Neurosci 15:2445-2452.

Tecott LH, Maricq AV, Julius D (1993) Nervous system distribution of the serotonin 5- $\mathrm{HT}_{3}$ receptor mRNA. Proc Natl Acad Sci USA 90:1430-1434.

Turner TJ, Mokler DJ, Luebke JI (2004) Calcium influx through presynaptic $5-\mathrm{HT}_{3}$ receptors facilitates GABA release in the hippocampus: in vitro slice and synaptosome studies. Neuroscience 129:703-718.

Van Praag HM (2004) Can stress cause depression? Prog Neuropsychopharmacol Biol Psychiatry 28:891-907.

Vertes RP (2004) Differential projections of the infralimbic and prelimbic cortex in the rat. Synapse 51:32-58.

Weiss B, Mertz A, Schrock E, Koenen M, Rappold G (1995) Assignment of a human homolog of the mouse Htr3 receptor gene to chromosome 11q23.1-q23.2. Genomics 29:304-305.

Wise RA (2000) Interactions between medial prefrontal cortex and mesolimbic components of brain reward circuitry. Prog Brain Res 126:255-262.

Wright CI, Fischer H, Whalen PJ, McInerney SC, Shin LM, Rauch SL (2001) Differential prefrontal cortex and amygdala habituation to repeatedly presented emotional stimuli. NeuroReport 12:379-383.

Zald DH (2003) The human amygdala and the emotional evaluation of sensory stimuli. Brain Res Rev 41:88-123. 